

\title{
A questão da (auto) identificação de comunidades tradicionais em teses e dissertações em Educação Ambiental do Brasil
}

\author{
Laura del Pilar Jiménez Sánchez ${ }^{1}$ \\ Universidade Estadual Paulista \\ ORCID: https://orcid.org/0000-0002-9712-2287 \\ Rosa Maria Feiteiro Cavalari ${ }^{2}$ \\ Universidade Estadual Paulista \\ ORCID: https://orcid.org/0000-0002-3782-2396
}

Resumo: O presente artigo tem por objetivo analisar teses e dissertações brasileiras em Educação Ambiental com comunidades/populações tradicionais, identificando as denominações usadas para os grupos sociais foco das produções e o respeito à autoidentificação das mesmas. Fez-se uma seleção das produções encontradas no banco do projeto "EArte Brasil" e no banco da Capes e da BDTD. A pesquisa qualitativa, do tipo "estado da arte" analisou vinte e nove teses e dissertações, das quais somente sete fazem referência à "autoidentificação" das comunidades. A designação feita por pessoas externas às comunidades pode determinar que os grupos sociais que recebem a denominação sejam vistos como "passivos". Tais representações são comuns no contexto das Ciências Sociais herdeiras do colonialismo ocidental que deixa de reconhecer seu papel nos processos de dominação global. É necessário construir diálogos horizontais nas pesquisas para dar visibilidade à realidade das comunidades como parte da luta por justiça socioambiental.

Palavras-chave: Pesquisa em educação ambiental. Comunidades tradicionais. Estado da arte.

\section{El problema de la (auto) identificación de comunidades tradicionales en tesis de maestría y doctorado en Educación Ambiental de Brasil}

Resumen: El artículo tiene como objetivo analizar tesis brasileñas de maestría y doctorado en Educación Ambiental con comunidades/poblaciones tradicionales, identificando las denominaciones usadas para referirse a los grupos sociales foco de las producciones, y el respeto a la autoidentificación de las mismas. Se hizo una selección de los documentos encontrados en el banco de los proyectos "EArte Brasil" y en el banco de la Capes y de la BDTD. La investigación cualitativa, tipo "estado del arte" analizó veintinueve trabajos, de los cuales, solamente siete hacen referencia a la "autoidentificación" de las comunidades. La designación hecha por

\footnotetext{
${ }^{1}$ Bióloga, Licenciada em Ciências Biológicas e Mestre em Educação, Unesp Rio Claro. E-mail: laura.jimenez@unesp.br

${ }^{2}$ Professora Dra do Departamento de Educação, Instituto de Biociências, Unesp Rio Claro. E-mail: r.cavalari@unesp.br
} 
personas externas a la comunidad puede determinar que los grupos sociales sean vistos como "pasivos". Dichas representaciones son comunes en el contexto de las Ciencias Sociales herederas del colonialismo occidental que deja de reconocer su papel en los procesos de dominación global. Se hace necesario construir diálogos horizontales en las investigaciones para darle visibilidad a la realidad de las comunidades, como parte de la lucha por justicia socioambiental.

Palabras-clave: Investigación en educación ambiental. Comunidades tradicionales. Estado del Arte.

\title{
The issue of (self) identification of traditional communities in
} theses and dissertations of Environmental Education in Brazil

\begin{abstract}
The present article has the objective of analyzing Brazilian thesis of masters and doctorate in Environmental Education with traditional communities / populations, identifying the denominations used to refer to the social groups that are the focus of production, and the respect for the self-identification. A selection of the masters and doctoral theses found in the "Earte Brasil" and Capes and BDTD thesis bank was made. The qualitative investigation, type "state of the art" analyzed twenty-nine documents, but only seven made reference to the "self-identification" process of the communities. The designation chosen by people external to the community could determine that social groups are seen as "passive". These representations are usual in the context of the Social Sciences inherited from Western colonialism that doesn't recognize their role in the processes of global domination. It is necessary to build horizontal dialogues in investigations to give visibility to the reality of communities, as part of the struggle for socioenvironmental justice.
\end{abstract}

Keywords: Environmental education research. Traditional communities. State of art.

\section{Introdução}

Como sociedade, atravessamos uma crise sem precedentes. As desigualdades sociais não só se explicitaram com a pandemia da Covid-19, mas se aprofundaram, expondo cada vez mais grupos à margem da sociedade. É o caso das denominadas "comunidades tradicionais" que, além da vulnerabilidade frente ao vírus, travam uma luta que data da colonização. Sua história não começou nesse momento, porém, após este marco, se iniciou um intenso período de apagamento e de genocídio que, segundo Ribeiro (2014), muitas vezes é romantizado com o intuito de exaltar os conquistadores, uma vez que só sua versão dos fatos acabou sendo contada nos livros de História.

Dado o apagamento e o silenciamento sofrido pelos povos tradicionais, grande parte dos conhecimentos foi se perdendo, ficando à margem da história na América-latina e, portanto, no Brasil. Segundo Pacheco e Faustino (2013, p. 78) este processo de colonização "conjugava expansão mercantil, racismo e dominação étnica", e com o capitalismo "se reinstitui na forma das grandes corporações nacionais e transnacionais, dos organismos multilaterais dominados pelos países do Norte que pressionam os territórios, suas populações e ecossistemas". Sendo assim, segundo as autoras, estas comunidades fazem 
parte dos grupos socioambientalmente mais "vulnerabilizados", considerando o processo histórico de marginalização dos mesmos.

No atual contexto do neoliberalismo, segundo Mbembe (2014) se produz indiferença, se codifica a vida social em normas e números, com a pretensão de "racionalizar o mundo a partir de lógicas empresariais" (p. 13). O "Neoliberalismo" se tornou, mais que uma ideologia de impacto econômico, uma racionalidade que preza pelo individualismo e pelo capital. A economia não pode parar, tudo passa a ter valor de mercado, e os recursos naturais não escapam dessa lógica, uma vez que a palavra de ordem é a acumulação. E, uma vez que os recursos passam a ter preço, os territórios onde se encontram são disputados, no entanto, em muitos residem comunidades tradicionais.

Ao mesmo tempo, a disputa pela exploração dos recursos levantou uma série de debates em torno da conservação de alguns desses espaços. A preocupação para preservar áreas naturais, que resultou em convenções internacionais sobre áreas protegidas, originou, entre outras medidas, sistemas de conservação de espaços muitas vezes habitados por comunidades tradicionais. Contudo, as primeiras legislações, baseadas na "política conservacionista" dos Estados Unidos, não levavam em consideração as comunidades que habitam e vivem desses territórios (DIEGUES, 2000).

E é nesse contexto que a realidade destes grupos começou a ganhar visibilidade, principalmente por serem considerados, por um lado, um obstáculo para o avanço do capitalismo, e por outro, um empecilho para a conservação das áreas.

Na metade da década de 1980, no contexto internacional relativo ao debate sobre áreas de preservação, surgiu a preocupação com os grupos humanos que ocupavam as áreas a serem preservadas, surgindo a necessidade de identificá-los (CASTRO; OLIVEIRA, 2016). Apesar de terem sido reconhecidas legislativamente, do ponto de vista da política conservacionista, não houve um reconhecimento das questões sociais reivindicadas por esses grupos. Porém, segundo Castro e Oliveira (2016, p. 52) a atuação de alguns dos "novos movimentos sociais", entre eles, o movimento ambientalista, "que mais tarde deram origem ao socioambientalismo, contribuiu para dar maior visibilidade e reconhecimento às populações tradicionais pelo poder público". 
Para Cunha e Almeida (2010) os grupos tradicionais também têm em comum o interesse em manter ou em recuperar o controle sobre seu território. Embora as comunidades sejam múltiplas e diversas, no decorrer da história, parece que tomaram os povos indígenas como modelos, apesar de esses grupos indígenas terem uma distinção legal com legislação específica. Assim, ao contrário das comunidades classificadas como "tradicionais", que em troca de direitos sobre seu território comprometem-se a prestar "serviços ambientais", os direitos territoriais indígenas não são qualificados com base em termos de conservação, mesmo quando suas terras possam figurar como "ilhas de conservação" em territórios de crescente devastação (CUNHA; ALMEIDA, 2010). Em decorrência disso, esses autores afirmam que a categoria dos povos indígenas não se encaixa na categoria mais ampla de comunidades tradicionais, e é necessário fazer distinção entre as duas.

Identificar estudos com estas comunidades não indígenas serve para traçar um panorama sobre os grupos que aparecem recorrentemente, assim como aqueles que aparecem pouco ou não aparecem como foco de estudos.

Dado o atual cenário de precarização de órgãos de fiscalização socioambiental como - Ibama, por exemplo, além do retrocesso relativo às políticas ambientais e desprezo pelas comunidades tradicionais demonstrado pelo governo do presidente Jair Bolsonaro, é urgente debater a realidade destas populações como parte das bandeiras de um movimento socioambiental preocupado com a justiça e a reparação histórica destes grupos, conhecidos pela defesa das áreas perante o avanço do capitalismo.

Neste artigo a discussão gira em torno da questão relativa à autoidentificação das comunidades com um ou outro grupo nas pesquisas em Educação Ambiental no Brasil, assim como da identificação feita por pessoas externas às populações. Para tanto serão apresentados, a seguir, os procedimentos de pesquisa.

\section{Procedimentos de pesquisa}

A pesquisa, de natureza qualitativa, que se caracteriza como "estado da arte" ou "estado do conhecimento", segundo Megid Neto e Carvalho (2018) é conhecida também 
como "metapesquisa", ou seja, pesquisas sobre pesquisas, e tem como objeto o conjunto de conhecimentos produzidos em um campo. Segundo Megid Neto (2009, p. 97-98), estas pesquisas "têm um caráter de revisão bibliográfica e, ao mesmo tempo, de especulação futura e de iluminação de novos caminhos para o campo em questão".

No caso dessa investigação o corpus documental é constituído por teses e dissertações pois estas produções são consideradas como "produções primárias", já que constituem relatórios completos de pesquisa, sendo delas que decorrem os artigos científicos, comunicações de eventos, entre outras produções (CARVALHO; MEGID NETO, 2018).

A pesquisa se insere no âmbito do Projeto Interinstitucional “EArte: Estado da Arte da Pesquisa em Educação Ambiental no Brasil" idealizado inicialmente pelo grupo FORMAR Ciências, da Faculdade de Educação da Unicamp, sendo retomado em 2008 por pesquisadores da Universidade Estadual Paulista (UNESP) Rio Claro, Universidade de São Paulo (USP) Ribeirão Preto e Universidade Estadual Paulista (UNICAMP). Atualmente outras instituições públicas participam do projeto Instituto Federal de Educação, Ciência e Tecnologia de São Paulo (IFSP) Itapetininga, Universidade Federal do Triângulo Mineiro (UFTM), Universidade Federal do Paraná (UFPR) e Universidade Federal Fluminense (UFF). Como parte do projeto houve a sistematização das teses e dissertações em Educação Ambiental no Brasil em um banco de dados aberto ao público.

Para a constituição do corpus documental dessa investigação definimos o seguinte caminho metodológico: definição dos termos de busca; "leitura flutuante" (BARDIN, 2009) dos resumos encontrados; definição de critérios para seleção; busca e leitura dos trabalhos completos e constituição do corpus definitivo, apresentado a seguir no Quadro 1:

Quadro 1: Corpus documental definitivo organizado temporalmente das produções mais antigas às mais recentes, com a identificação do trabalho (ID), termo de busca e referência.

\begin{tabular}{|l|l|l|}
\hline & $\begin{array}{l}\text { Ter } \\
\text { mo } \\
\text { de } \\
\text { bus } \\
\text { ID }\end{array}$ & \\
\hline ca & Referência \\
\hline T1 & PT & $\begin{array}{l}\text { RODRIGUES, Eliana. Moradores do Parque Nacional do Jaú, AM: espaço e cultura. } 1997 . \\
\text { Dissertação (Mestrado em Geografia). Universidade de São Paulo, São Paulo, } 1997 .\end{array}$ \\
\hline
\end{tabular}




\begin{tabular}{|c|c|c|}
\hline $\mathrm{T} 2$ & PT & $\begin{array}{l}\text { dilza Laray de. Sociodiversidade no Jaú: a ética do com-viver. 1998. Dissertação (Mestrado } \\
\text { cação ambiental). Fundação Universidade do Rio Grande, Rio Grande do Sul, } 1998 .\end{array}$ \\
\hline T3 & CT & $\begin{array}{l}\text { ALMEIDA, Henrique Luís de Paula. Indicadores de qualidade de vida instrumento para o } \\
\text { monitoramento participativo da qualidade de vida de comunidades costeiras tradicionais: o caso } \\
\text { da Prainha do Canto Verde, Beberibe/CE. 2002. Dissertação (Mestrado em Desenvolvimento e Meio } \\
\text { Ambiente). Universidade Federal de Ceará, Fortaleza- CE, 2002. Disponível em: } \\
\text { http://repositorio.ufc.br/handle/riufc/15743 }\end{array}$ \\
\hline T4 & CT & $\begin{array}{l}\text { FERRAZ, Maria Luiza Camargo Pinto. Educação ambiental contínua: a vida com o foco da } \\
\text { aprendizagem o caso da escola Maria Elisbânia dos Santos - comunidade de Caetanos de Cima } \\
\text { Assentamento Sabiaguaba -Amontada/CE. 2004. Dissertação (mestrado, em Desenvolvimento e } \\
\text { Meio Ambiente). Universidade Federal do Ceará, Fortaleza-CE, 2004. Disponível em: } \\
\text { http://repositorio.ufc.br/handle/riufc/16860 }\end{array}$ \\
\hline T5 & $\mathrm{P}$ & $\begin{array}{l}\text { LUSTOSA, Ana Helena Mendes. Práticas produtivas e (in) sustentabilidade: os catadores de } \\
\text { caranguejo do Delta do Parnaíba. 2005. Dissertação (Mestrado em Desenvolvimento e Meio } \\
\text { Ambiente). Universidade Federal do Piauí, Teresina- Pl, } 2005 \text {. }\end{array}$ \\
\hline T6 & CT & $\begin{array}{l}\text { KASSEBOEHMER, Ana Lívia. Restrições e impactos da legislação ambiental aplicada no município de } \\
\text { Guaraqueçaba, Paraná. 2007. Dissertação (Mestrado em Engenharia Florestal). Universidade } \\
\text { Federal do Paraná, Curitiba, 2007. Disponível em: http://www.floresta.ufpr.br/pos- } \\
\text { graduacao/defesas/pdf ms/2007/d477 } 0665-\mathrm{M} \text {.pdf }\end{array}$ \\
\hline T7 & CT & $\begin{array}{l}\text { ZAPPES, Camilah Antunes. Estudo etnobiológico comparativo do conhecimento popular de } \\
\text { pescadores em diferentes regiões do litoral brasileiro e implicações para a conservação do boto- } \\
\text { cinza Sotalia guianensis (Van Bénéden, 1864)(Cetacea, Delphinidae). 2007. Dissertação (Mestrado } \\
\text { em Ciências Biológicas) Universidade Federal de Juiz de Fora, Juiz de Fora, 2007. }\end{array}$ \\
\hline T8 & PT & $\begin{array}{l}\text { ental de áreas úmidas por uma } \\
\text { aquari-Antas, Rio Grande do Sul. } \\
\text { do Rio do Sinos, 2007. Disponível }\end{array}$ \\
\hline T9 & CT & 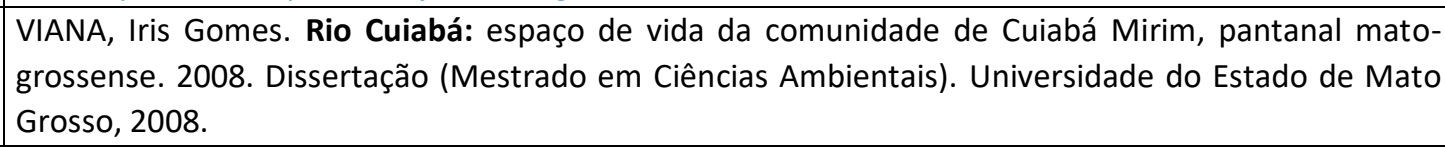 \\
\hline $\mathrm{T} 1$ & PT & $\begin{array}{l}\text { ra do } \\
\text { rana, }\end{array}$ \\
\hline $\mathrm{T} 1$ & $\begin{array}{l}\text { CT } \\
\& \\
\text { PT } \\
\end{array}$ & $\begin{array}{l}\text { de campo com comunid } \\
\text { de Ilhabela. 2010. Disse }\end{array}$ \\
\hline $\mathrm{T} 1$ & CT & de Sãabá, \\
\hline $\begin{array}{l}\mathrm{T} 1 \\
3\end{array}$ & C & 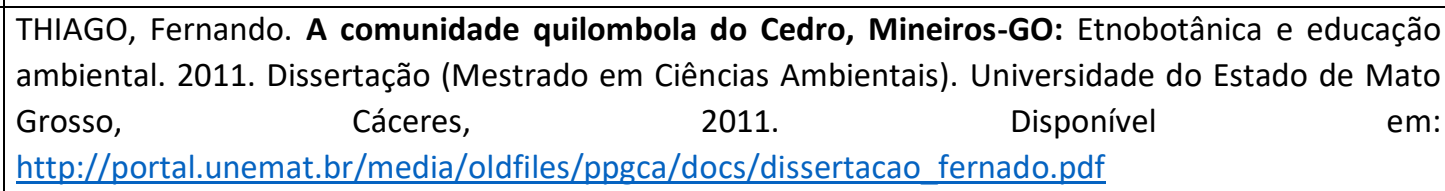 \\
\hline $\begin{array}{l}\mathrm{T} 1 \\
4\end{array}$ & PT & $\begin{array}{l}\text { PEREIRA, Bárbara Elisa. Crianças Caiçaras de Guaraqueçaba: PR Relações com a natureza. 2011, } 221 \\
\text { f. Dissertação (Mestrado em Ciência Ambiental). Universidade de São Paulo, } 2011 .\end{array}$ \\
\hline $\mathrm{T} 1$ & PT & $\begin{array}{l}\text { LOUZADA, Leny Xavier. Os impactos socioambientais da implementação da reserva de } \\
\text { desenvolvimento sustentável do Tupé na comunidade Nossa Senhora do Livramento. } 2011 . \\
\text { Dissertação (Mestrado em Serviço Social). Pontifícia Universidade Católica, Rio de Janeiro, } 2011 .\end{array}$ \\
\hline
\end{tabular}




\begin{tabular}{|c|c|c|}
\hline & & \\
\hline $\mathrm{T} 1$ & C & $\begin{array}{l}\text { RATA, Jade Prata Bueno. Educação entre alienação e emancipação: um estudo de caso do } \\
\text { uilombo Campinho da Independência, Parati, RJ. 2013. Dissertação (Mestrado em Psicossociologia } \\
\text { Comunidades e Ecologia Social). Universidade Federal de Rio de Janeiro, Rio de Janeiro, } 2013 .\end{array}$ \\
\hline $\begin{array}{l}\mathrm{T} 1 \\
7\end{array}$ & PT & $\begin{array}{l}\text { CRUZ, Walcicléa Purificação da Silva. Educação e conservação da biodiversidade no contexto } \\
\text { escolar da reserva extrativista Terra Grande Pracuúba. 2014. Dissertação (Mestrado em Educação). } \\
\begin{array}{lllll}\text { Universidade } \quad \text { Federal do Pará, } & \text { Belém, } & \text { 2014. Disponível em: } \\
\text { http://repositorio.ufpa.br/jspui/bitstream/2011/6179/1/Dissertacao EducacaoConservacaoBiodiver }\end{array} \\
\text { sidade.pdf }\end{array}$ \\
\hline $\mathrm{T} 1$ & CT & $\begin{array}{l}\text { FOPPA, Carina Catiana. Comunidades tradicionais em movimento: modos de vida e educação } \\
\text { ambiental para o desenvolvimento territorial sustentável em uma unidade de conservação } \\
\text { marinho-costeira no litoral de Santa Catarina. 2015. Tese (Doutorado em Educação Ambiental) - } \\
\text { Faculdade de Educação Ambiental. Universidade Federal do Rio Grande, 2015. Disponível em: } \\
\text { http://repositorio.furg.br/handle/1/8427 }\end{array}$ \\
\hline $\mathrm{T} 1$ & C & $\begin{array}{l}\text { S Nogueira. Turismo em comunidades na busca do desenvolvimento } \\
\text { E. 2015. Dissertação (Mestrado em Gestão de Negócios Turísticos). } \\
\text { á, 2015. }\end{array}$ \\
\hline $\mathrm{T} 2$ & PT & $\begin{array}{l}\text { ão das diferentes pessoas envolvidas sobre a reserva } \\
\text { ambiental realizada nesta reserva e a questão da dragagem } \\
\text { estrado em Gestão Social, Educação e Desenvolvimento } \\
15 .\end{array}$ \\
\hline T2 & PT & $\begin{array}{l}\text { Educação ambiental e sustentabilidade para problemas } \\
\text { os: um estudo de caso sobre o Farol de Santa Marta, Laguna, } \\
\text { ncias Ambientais). Universidade do Extremo Sul Catarinense, } \\
\text { /download/pdf/297692386.pdf }\end{array}$ \\
\hline $\begin{array}{l}\mathrm{T} 2 \\
2\end{array}$ & CT & 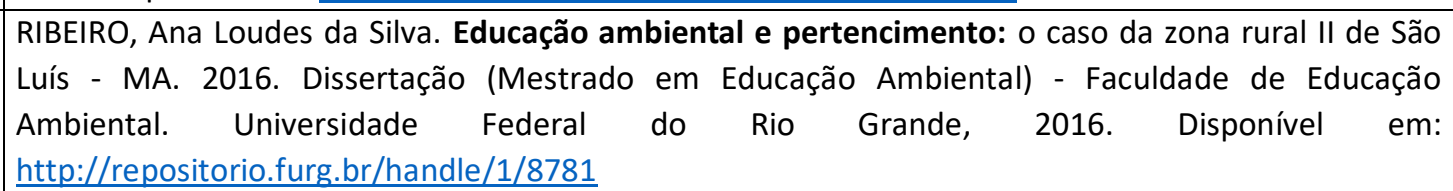 \\
\hline $\begin{array}{l}\text { T2 } \\
3\end{array}$ & C & $\begin{array}{l}\text { biental dialógico-crítica no Pantanal de Mato Grosso: a voz } \\
\text { scadores tradicionais. 2017. Tese (Doutorado em Ciências } \\
\text { I de São Carlos, São Carlos, 2017. Disponível em: } \\
\text { car/9021. }\end{array}$ \\
\hline $\mathrm{T} 2$ & CT & $\begin{array}{l}\text { DIAS, Gizelle dos Santos. O processo educacional no remanescente de Quilombo Volta Miúda como } \\
\text { forma de promover a valorização ambiental em comunidades tradicionais. } 2017,107 \text { f. Dissertação } \\
\text { (Mestrado em Gestão Social, Educação e Desenvolvimento Regional). Faculdade Vale do Cricaré, São } \\
\begin{array}{lll}\text { Mateus, } & \text { Disponível } \\
\text { https://sucupira.capes.gov.br/sucupira/public/consultas/coleta/trabalhoConclusao/viewTrabalhoCo }\end{array} \\
\text { nclusao.jsf?popup=true\&id trabalho=4665352 }\end{array}$ \\
\hline $\begin{array}{l}\text { T2 } \\
5\end{array}$ & CT & 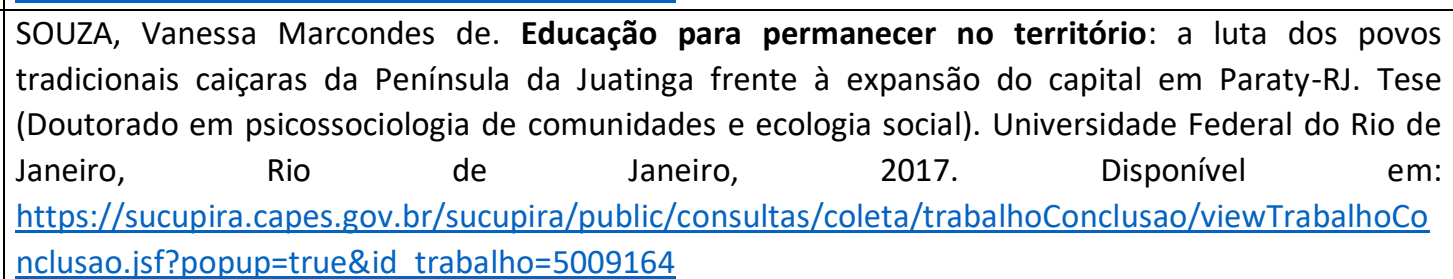 \\
\hline $\mathrm{T} 2$ & CT & $\begin{array}{l}\text { Campos Pereira. Educação Ambiental para Comunidades Rurais: reflexões e } \\
\text { tação (Mestrado em Conservação da Biodiversidade e } \\
\text { tentável). Instituto de Pesquisas Ecológicas, Nazaré Paulista, 2017. Disponível }\end{array}$ \\
\hline
\end{tabular}




\begin{tabular}{|l|l|l|l|l|}
\hline & & $\begin{array}{l}\text { em: } \\
\text { Botelho.pdf }\end{array}$ \\
\hline T2 & CT & $\begin{array}{l}\text { SANTOS, Kelly Polyana Pereira dos. Etnozoologia e etnoecologia na comunidade de pescadores } \\
\text { artesanais do município de Miguel Alves, PI/Brasil. 2018. Tese (Doutorado em Desenvolvimento e } \\
\text { Meio Ambiente). Universidade Federal do Piauí, Teresina - PI, 2017. Disponível em: } \\
\text { https://repositorio.ufpi.br/xmlui/handle/123456789/1433 }\end{array}$ \\
\hline T2 & CT & $\begin{array}{l}\text { SILVA-MENESES, Fernanda Vera Cruz. Conhecimento local e percepção ambiental de pescadores } \\
\text { artesanais: uma estratégia de educação ambiental. 2018. Dissertação (Mestrado em Planejamento } \\
\text { Ambiental). Universidade Católica do Salvador, Salvador, 2018. Disponível } \\
\text { http://ri.ucsal.br:8080/jspui/bitstream/prefix/405/5/DISSERTACAOFERNANDAMENESES.pdf }\end{array}$ \\
\hline $\begin{array}{l}\text { T2 } \\
9\end{array}$ & CT & $\begin{array}{l}\text { MANFRINATE, Rosana. Fontes do imaginário e da educação ambiental: cartografia e justiça } \\
\text { climática nas águas e sentidos das mulheres pantaneiras, quilombolas e mariscadoras. 2018, 279 f. } \\
\text { Tese (Doutorado em Educação) - Universidade Federal de Mato Grosso, Cuiabá, 2018. Disponível em: } \\
\text { https://ri.ufmt.br/handle/1/1549 }\end{array}$ \\
\hline
\end{tabular}

Legenda: PT - População Tradicional; CT - Comunidade tradicional.

Fonte: Elaborado pela autora com base nos dados institucionais das pesquisas

As buscas foram realizadas em três bancos de dados: o do projeto EArte, que até o momento contém as teses e dissertações até o ano de 2016; o da Capes que é o da Plataforma Sucupira, para as buscas relativas aos anos de 2017 e 2018, e o da Biblioteca Digital Brasileira de Teses e Dissertações (BDTD). Os dois últimos, são os principais bancos de referência do primeiro.

No total, vinte e nove trabalhos, sendo cinco teses de doutorado, e vinte e quatro dissertações de mestrado, constituem o corpus documental final, desses, vinte e dois foram produzidos em instituições públicas.

\section{Autoidentificação das Comunidades Tradicionais nas Teses e Dissertações}

A partir da leitura detalhada do corpus documental, foram identificadas as comunidades/populações tradicionais focos das pesquisas, apresentadas no Quadro 1. Nos atentamos para manter as exatas denominações adotadas nas teses e dissertações:

Tabela 1: Comunidades/populações tradicionais identificadas nas teses e dissertações. Legenda: "/" significa "ou", quer dizer que a comunidade recebe mais de uma denominação no decorrer do texto; "," significa " $e$ ", quer dizer que o trabalho trata de mais de uma comunidade/população

\begin{tabular}{|l|l|}
\hline Comunidades foco & Número de produções \\
\hline Caiçara & 3 \\
\hline costeira/ litorânea & 2 \\
\hline
\end{tabular}




\begin{tabular}{|l|l|}
\hline pescadores artesanais & 2 \\
\hline Rural & 2 \\
\hline catadores caranguejo & 1 \\
\hline pantaneira, quilombola, marisqueira (ES) & 1 \\
\hline ribeirinha/ rural & 1 \\
\hline ribeirinha, pescadores, extrativistas & 1 \\
\hline extrativista/ povos da floresta & 1 \\
\hline Remanescente de Quilombo/ Quilombo contemporâneo* & 1 \\
\hline caiçara (pescadores artesanais e agricultores familiares) & 1 \\
\hline quilombola* & 1 \\
\hline pantaneiras/ribeirinhas & 1 \\
\hline quilombola emergente* & 1 \\
\hline não define por respeito à autoidentificação & 1 \\
\hline pescadores de lagosta/ pesqueira & 1 \\
\hline ribeirinhas (ribeirinhos ou pantaneiros) & 1 \\
\hline pescadores artesanais/ caiçaras & 1 \\
\hline caiçara (pescadores artesanais) / insulares & 1 \\
\hline caboclos, nordestinos & 1 \\
\hline Ribeirinhas & 1 \\
\hline ribeirinhas/ pescadores artesanais & 1 \\
\hline pescadoras/es* & 1 \\
\hline pescadores artesanais (pescadores e marisqueiras) & 1 \\
\hline Total geral & $\mathbf{2 9}$ \\
\hline
\end{tabular}

Fonte: Elaborado pela autora, de acordo com os dados das pesquisas

As comunidades com asterisco $\left({ }^{*}\right)$ na tabela são as que fazem referência à autoidentificação.

Os trabalhos T1 e T2 foram desenvolvidos no mesmo local, o Parque Nacional do Jaú, com financiamento da mesma ONG, e com diferença de um ano, 1997 e 1998 respectivamente. Porém, cada trabalho usa diferente denominação para os grupos sociais que habitam a região. Segundo o T1, como apresentado no excerto a seguir, denomina a população como "ribeirinha": "População tradicional ribeirinha [7], que subsiste em estreita relação com os elementos biológicos e físicos desse meio." (T1, p. 18)

Ao caracterizar a comunidade foco da pesquisa, o trabalho se fundamenta em diferentes autores, citando a comunidade como fruto de miscigenação, que também é citada em T2. Segundo a pesquisa, este processo deu origem a diversidade de populações como sendo resultado da colonização, do genocídio dos grupos indígenas, e da demanda do 
mercado capitalista que ocasionou migrações para a região, caracterizando as populações como formadas por "caboclos e nordestinos" (T2, p. 63). Em relação ao termo "caboclo", é uma denominação que gera controvérsias. De acordo com Lima (1999) pode ter sua origem da palavra tupi caa-boc. Este termo significa "o que vem da floresta" (COSTA PEREIRA, 1975). Outra possível origem é da palavra tupi kari'boka, que significa "filho do homem branco" (Ferreira, 1971).

Segundo Pace (2006), o termo originalmente era utilizado pelos grupos indígenas da costa ao se referirem aos grupos indígenas do interior. Nos períodos históricos seguintes o termo foi mudando, ganhando outros significados, sendo que, na literatura das Ciências Sociais o termo possui várias definições, algumas delas associadas à miscigenação dos grupos indígenas com outros grupos (PACE, 2006).

Outras definições são relativas ao sistema político econômico ou a adaptação ecológica, ou ainda à questão cultural, sendo que, em todas as definições se encontra a ideia de que não são indígenas nem colonos. Porém, segundo Pace (2006) na Amazônia brasileira, o termo vem carregado de uma conotação negativa, sendo usado para designar pessoas com baixa condição social, preguiçosas, traiçoeiras, desinformadas, analfabetas, entre outros adjetivos. Nesse sentido, "é um termo definido por oposições de superioridade e inferioridade" (Pace, 2006, p. 82). Exemplos das oposições, citadas por Lima (1999) são civilizado/selvagem, cidade/floresta, rico/pobre. Ainda segundo Pace, (2006) o termo é majoritariamente usado por pessoas que não se reconhecem como tal, pois aquelas que se identificam como "caboclas" raramente usam o termo, a não ser em situações que queiram rebaixar ou fazer piadas com alguém, e em menor proporção em situações positivas.

Segundo a pesquisa de Pace (2006) em Gurupá/AM, 35\% das pessoas entrevistadas consideram o termo ofensivo quando aplicada a elas, sendo que os $65 \%$ que não consideram desta forma compreendem que existe uma conotação pejorativa. Sendo assim, o autor questiona o uso do termo nas produções acadêmicas, considerando a carga negativa que tem para as comunidades. Para Pace (2006) esta questão está relacionada à mudança de paradigma nas Ciências Sociais que se intensificou nos anos 1960, que entre outras coisas, apresentou uma crítica às relações de poder na construção do conhecimento etnográfico. 
Segundo Lima (1999), no discurso coloquial e na literatura acadêmica, o termo "caboclo" tem significados diferentes. No primeiro é uma categoria ambígua que no contexto amazônico pode estar associada a um estereótipo negativo, relativo tanto a questão geográfica, quanto a divisão social; já no segundo, faz referência aos "pequenos produtores rurais de ocupação histórica" (Lima, 1999, p. 5). De acordo com a autora, na Antropologia esta é uma categoria social fixa, que remete ao "campesinato histórico da Amazônia" (Lima, 1999, p. 7). Segundo a autora:

\footnotetext{
Embora o termo transmita um significado preciso aos leitores em potencial desses trabalhos acadêmicos, ele deixa uma pergunta a ser respondida: se é um termo de identificação do observador, qual é a identidade própria das pessoas às quais o termo se refere? Os chamados caboclos, isto é, os pequenos produtores rurais amazônicos, não têm uma identidade coletiva, nem um termo alternativo e abrangente de autodenominação. A única categoria de autodenominação comumente empregada por toda a população rural é a de "pobre". (Lima, 1999, p. 8).
}

A pergunta apresentada pela autora foi uma preocupação recorrente nas leituras dos documentos quando buscamos investigar quais comunidades são foco das pesquisas que compõem o corpus documental. Mais do que só elencar os grupos, esta abordagem é importante para pensar a própria prática cientifica, procurando saber se as pesquisas tiveram a preocupação em ouvir as comunidades e sua percepção sobre as identidades culturais construídas dentro e fora dos grupos sociais.

No caso do termo "caboclo", para Lima (1999) o fato de não ser usado na autodenominação está relacionado com a conotação pejorativa já mencionada, que entre a população rural transmite a ideia de "índio domesticado", sendo uma maneira de estes grupos sociais assumirem uma posição inferior (p. 21). Outra possível razão apontada pela autora é que o termo nunca foi associado a um movimento político, como é o caso dos indígenas, cuja designação ganhou um valor político positivo e acabou sendo aceito enquanto termo de autodenominação. Em relação a estes grupos sociais, Lima (1999) e Pace (2006) afirmam que há poucos estudos com estas comunidades, fato que pode ter contribuído para que os conhecimentos científicos produzidos sobre essas comunidades pareçam distantes de conhecer a identidade das mesmas. Apesar disso, a questão da miscigenação é um fator comum nas diversas tentativas de compreensão destes grupos. 
Nesse sentido, observamos que dezesseis trabalhos, T1, T2, T3, T4, T5, T6, T9, T10, T11, T14, T15, T18, T21, T22, T25, T28 fazem referências às comunidades indígenas em diversos trechos dos textos, associados majoritariamente à sua relação com a natureza, como exemplo, de legado para as comunidades atuais, e/ou quando descrevem processos históricos das populações tradicionais no Brasil, principalmente relativos à colonização e à miscigenação que, segundo as produções, deu origem as comunidades foco dessas pesquisas.

É importante apontar que, segundo Cunha (2009), este processo de miscigenação se deu no primeiro momento por acordos entre indígenas e portugueses, no período prévio à colonização propriamente dita, e em segundo lugar, por meio da violência. Segundo a autora também ocorreram casamentos entre indígenas e mulheres negras escravizadas, estimulados pelos senhores que buscavam atrair indígenas para fora de suas aldeias onde estavam sob jurisdição de missionários, dificultando o processo de escravizá-los. Depois de 1795 com as "reformas pombalinas" a miscigenação começou a ser promovida pelo próprio estado, estimulando com regalias casamentos entre brancos e mulheres indígenas (Cunha, 2009).

A questão neste ponto é que o processo de miscigenação normalmente não aparece sendo problematizado. Como vemos nos excertos, ele somente é citado, de forma que não há um destaque para as violências sofridas principalmente pelas mulheres indígenas e negras: o estupro que deu origem a grande parte da população dos países colonizados.

Sendo assim veicula a ideia de que foi um processo "natural" e pacífico invisibilizando a misoginia e o preconceito racial e étnico por trás da miscigenação. É o mesmo que ocorre quando se fala da colonização como a chegada pacifica dos europeus que trouxeram a "civilização" para os povos "primitivos". Segundo Ribeiro (2014) houve manipulação nos dados apresentados em relação a população que havia antes da colonização, com a intenção de dignificar o papel dos colonizadores "ocultando o peso do seu impacto genocida sobre as populações americanas" (p. 142).

O fato de que isto continue sem ser exposto nas produções acadêmicas reforça o pressuposto de que a ciência não é neutra, pois muitas vezes narra o ponto de vista de quem venceu nos conflitos, sendo normalmente quem tem mais poder aquisitivo, ou quem está no 
topo das relações de poder. Em outras palavras, quem conta a história muitas vezes foi quem oprimiu e violentou outros povos ou grupos sociais, que era também quem tinha condições econômicas suficientes para ter formação acadêmica e, assim, reproduzir seu lado da história nos escritos.

Essa naturalização e apagamento da violência na história da conformação do povo brasileiro deram origem ao "mito da democracia racial". Segundo Gonzales (1984), como todo mito, este "oculta algo para além daquilo que mostra" (p. 228), neste caso, exercendo sua "violência simbólica". Tal mito nada mais é do que a crença de que não existe racismo no Brasil, usado para deslegitimar movimentos que reivindicam oportunidades para grupos marginalizados historicamente, como as cotas para ingresso nas universidades que vem sendo questionadas pelo atual governo, assim como o dirigente da Fundação Palmares da qual discutiremos mais adiante.

Em continuidade às análises realizadas, de acordo com as pesquisas T6 e T10, realizadas na mesma UC, as populações foco do estudo são "caiçaras". Nos trabalhos T11, T14 e T25 também são denominadas dessa forma, sendo que, no T11 esta categoria engloba a de "pescadores tradicionais". Segundo o T10 com base no autor Diegues, a comunidade caiçara foco desse estudo, é caracterizada como vemos no excerto a seguir:

\footnotetext{
Segundo Diegues (2006), os caiçaras que habitam a região do PARNA do Superagui fazem parte de uma cultura crioula ou cabocla, originaria do aporte cultural dos europeus, negros e índios. Sobre a cultura caiçara tem-se o seguinte relato: "[...] a associação entre pesca e agricultura, a importância do 'complexo farinha de mandioca', as relações sociais individualizadas em grupo maior e na família nuclear, através de mutirões, a reciprocidade na vida quotidiana, a falta de uma noção de autoridade formal, a pouca importância dada à religião oficial, estão entre as principais características da cultura caiçara." (DIEGUES, 2006). (T10, p. 60, 61)
}

Como exposto em relação às comunidades caboclas, Campos (2008) também faz referência ao fato de a identidade caiçara ser associada a um modo de viver oposto ao encontrado nas cidades. Em relação à caracterização do trabalho T25, será apresentada oportunamente uma vez que trata da questão da autoidentificação deste grupo como tal.

Relativo à origem do termo "caiçara", de acordo com Sampaio (1987) este derivou de caá-içara, do Tupi-Guarani, termo que fazia referência às estacas que eram colocadas ao redor das aldeias e ao curral feito de galhos para cercar os peixes na água. Com o tempo foi 
mudando de significado até que passou a ser usado para designar grupos sociais do litoral de São Paulo, Rio de Janeiro e Paraná.

Outra questão em comum apontada por Lima (1999) e por Campos (2008) na literatura que busca caracterizar populações caboclas e caiçaras, é a ausência feminina e das atividades realizadas pelas mulheres, apesar de que, segundo as autoras, as mulheres assumem tarefas centrais na vida das comunidades desenvolvendo diferentes papéis nestes grupos. Assim, de acordo com Campos (2008) a herança cultural e social das pessoas negras que foram sequestradas da África e chegaram ao Brasil em regime de escravidão tende a ser invisibilizada, mesmo na literatura acadêmica.

Por outro lado, os trabalhos T27 e T28 analisam comunidades que denominam de "pescadores artesanais". Segundo a pesquisa T28, estas populações tendem a se organizar nas denominadas "vilas", que contrastam com a sociedade capitalista, como vemos no trecho a seguir que destaca um ponto importante de choque cultural:

[...] o modelo de desenvolvimento capitalista empenha-se em descaracterizar vilas de pescadores, determinando-as como ex-vilas de pescadores, mesmo com a atividade marcada no modo de vida e na identificação da rotina da pesca artesanal no campo empírico, além do registro em documentos oficiais. Verifica-se que é muito comum outras vilas de pescadores inseridas em rotas turísticas no Estado da Bahia receberem essa mesma denominação (ex-vila). (T28, p.85)

Esta descaracterização também foi encontrada relativa à denominação de "remanescente de Quilombo" como vemos no excerto a seguir:

\footnotetext{
O debate sobre o discurso que trata dos quilombos é de suma relevância, pois a forma cristalizada deste discurso é eloquente e insere os quilombolas como "os que não têm história possível", (Fernando Henrique Cardoso, 1973 apud Gomes, 2006), ou seja um grupo em extinção, bem como aparece na constituição federal, "remanescentes" e infelizmente esta é a concepção mais forte presente na sociedade brasileira, inclusive nas escolas. (T16, p. 25)
}

Este excerto, assim como no T28 (das) relativo às "ex-vilas" citado anteriormente, denuncia um processo de descaracterização das comunidades. Neste caso, se trata de uma denominação amplamente conhecida e usada nas legislações e nas escolas. Em decorrência do uso destas denominações as comunidades vão sendo reduzidas ao que restou delas, 
tanto na legislação, quanto no imaginário popular, como se fizessem parte de um passado que foi ou precisa ser superado pela "civilização".

Ainda segundo o T16 "Quilombo" é uma "categoria em disputa", sendo que podem ser identificadas diferentes formas de "ressemantização de quilombo" (p. 39), como vemos no seguinte excerto que cita Arruti, autor muito referenciado quando o tema é comunidades quilombolas:

\begin{abstract}
A proposta de definição externa, de adequação em categorias, científica ou normativa sobre o outro, como populações quilombolas ou indígenas, em geral demonstra a relação de dominação e subjugação existente, assim, a definição é arbitrária defendendo interesses não autóctones (provenientes de dentro do sistema analisado). A redefinição das categorias em acordo com a realidade vivenciada e projetada pelos próprios sujeitos em uma relação dialética é a forma mais honesta de se contemplar as necessidades nomenclaturais para garantir a defesa de interesses das próprias populações. Assim, a nomenclatura "emergentes" (Arruti, 1997, p. 30) representa a proposta de construção atual do Quilombo e da identidade quilombola, não remete à manutenção museológica de costumes antepassados, mas não nega tais costumes, recontextualizando-os, assim numa reconstrução dialética dos interesses dos atuais quilombolas. A ideia de emergentes rompe também com o sentido de escasso que acompanha "remanescentes" (T16 p. 39, 40).
\end{abstract}

Sendo assim, segundo esta pesquisa, o significado das identidades deve ser questionado, principalmente devido a essa polissemia, sendo que uma categoria pode representar resistência ao capitalismo e outra a submissão. Desta forma, segundo o T16 a comunidade se identifica como "Quilombolas emergentes", dado sua luta de resistência.

Todavia, o T24 usa as denominações de "Remanescente de Quilombo" ou "Quilombo contemporâneo" (p. 44) como sinônimo. Em relação à segunda denominação, segundo T24 com base em Moura (2007) e a caracterização de acordo com Nascimento (1980):

Atualmente, podemos conceituar Quilombos Contemporâneos como comunidades negras rurais habitadas por descendentes de africanos escravizados, que mantêm laços de parentesco e vivem, em sua maioria, de culturas de subsistência, em terra doada, comprada ou ocupada secularmente pelo grupo (MOURA, 2007, p.10).

Nascimento (1980) salienta ainda que o Quilombo, enquanto sistema socioeconômico, revela-se como uma alternativa ao sistema capitalista, uma vez que, alguns desses remanescentes, seguindo os antecedentes históricos, vivem de forma comunitária, criativa, onde o trabalho não é visto como castigo ou exploração (T24, p. 25). 
Ainda de acordo com o trabalho, "Volta Miúda é uma comunidade que se auto reconheceu como remanescente de quilombo no ano de 2005 e que ainda espera a titulação de suas terras" (T24, p. 85). Contudo, é importante lembrar que, uma vez que a denominação oficial é "remanescente" pode haver uma tendência a aceitar essa categoria por parte de alguns grupos.

Nesse sentido, de acordo com Arruti (1997), esse debate conceitual teve contribuição do âmbito cientifico e do âmbito político, sendo que cada um com naturezas diferentes. Para o autor, o primeiro está engajado com as causas populares por meio de problemáticas com "origem em tradições disciplinares e debates conceituais"; já o segundo, está vinculado às lutas e causas de uma comunidade ou região (ARRUTI, 1997, p. 8). Assim, as analises cientificas e as interpretações e intervenções jurídicas acabam sendo dois universos distintos, por vezes distantes, até mesmo na linguagem.

Segundo Arruti (1997), o termo "remanescentes" foi atribuído, no contexto de emergência de grupos indígenas no Nordeste, uma vez que as pessoas responsáveis pela mediação entre estes grupos e instituições governamentais, viram a necessidade de nomear essas comunidades. De acordo com o autor, nos primeiros textos fica explicita a indecisão no uso dos termos, porém, com o tempo, a denominação de "remanescentes indígenas" foi ganhando destaque.

Porém este termo acaba fazendo referência a uma profunda perda cultural, e implicitamente denota uma transição entre o que seria o estado inicial do "bom selvagem" ao estado de civilização (Arruti, 1997). Para o autor, no caso das comunidades negras, a conotação é semelhante, reconhecendo as comunidades como formas atualizadas dos Quilombos. Assim, na década de 1970 com os estudos dos movimentos populares, os Quilombos passaram a ser vistos como símbolo de luta contra a ordem escravocrata, e até mesmo contra o capitalismo (Arruti, 197), como visto no excerto do trabalho T24. O autor afirma que estes grupos "remanescentes" passaram a serem reconhecidos como símbolos de luta, e o termo ganhou então positividade.

Ainda segundo Arruti (1997), fundamentando-se em Sider (1976), o processo de atribuição de direitos a estes grupos permitiu o processo de "etnogênese": 
Como apontou Sider (1976), se o etnocídio é o extermínio sistemático de um estilo de vida, em oposição a ele, a construção fraternal de uma autoconsciência e de uma identidade coletiva (de base racial e/ou histórica) contra a ação de um Estado Nacional opressor, com vistas a ganhos políticos, entre os quais pode-se encontrar alguma expectativa de autodeterminação, deve ser chamada de etnogênese (Arruti, 1997, p. 27).

Desta forma, a importância de reconhecer estes grupos como "emergentes" se dá em compreender que seu lugar ainda será feito por quem conseguir ocupá-lo, dentro da correlação de forças de suas lutas, sem esquecer da "plasticidade identitária" que marca muitas destas comunidades (ARRUTI, 1997, p. 30).

O T23, fundamentando-se em Touraine (1997) também discute a autoidentificação das pessoas da comunidade foco da pesquisa, como vemos no excerto a seguir:

[...] estas pessoas preferiram ser chamadas/os de pescadoras/es tradicionais. Diante disso é importante destacar que, apesar de vivermos em tempos de imposição capitalista de homogeneização cultural (TOURAINE, 1997) estas mulheres e estes homens afirmaram que, embora muitas/os delas/es tenham perdido o direito de uso de alguns apetrechos tradicionais ou o direito de permanência pacífica em seus territórios tradicionais de pesca (p. ex.) - inclusive onde várias/os delas/es nasceram - continuam se autorreconhecendo[13] como pescadoras/es pantaneiras/os tradicionais (T23, p. 21).

A nota de pé de página apresentada pelo trabalho a seguir, identificada pelo número [13], associada a este excerto, apresenta informações importantes em relação ao que denomina de "autorreconhecimento":

[13] No contexto da Política Nacional de Desenvolvimento Sustentável dos Povos e Comunidades Tradicionais o autorreconhecimento, ao lado de outras características arroladas no âmbito do Decreto 6.040/2007, é uma das características socioculturais elementares dos povos e comunidades tradicionais. Para esta tese, em função do contexto de conflitos socioambientais em que as pantaneiras e os pantaneiros estão implicadas/os adotamos a concepção proposta por Diegues (2001a), para quem o autoreconhecimento "é freqüentemente, nos dias de hoje, uma identidade construída ou reconstruída, como resultado, em parte, de processos de contatos cada vez mais conflituosos com a sociedade urbano-industrial, e com os neomitos criados por esta" (p.88) (T23, p. 21).

Para finalizar, após discutir as principais denominações das comunidades tradicionais encontradas nas teses e dissertações, avaliamos ser importante apresentar as considerações do trabalho T18 em relação a este tema. Tendo como referência Almudi; Kalikoski (2009) 
esta pesquisa não apresenta denominações para a comunidade foco, uma vez que, de acordo com o trabalho:

\begin{abstract}
As características apresentadas não pretendem definir a comunidade tradicional, visto que isso afastaria os princípios normativos que marcam a autodeterminação que permeia a temática. 0 esforço analítico, no entanto, recupera categorias importantes que compõe a complexidade de relações que configuram o território e oferecem pistas para compreender sua tradicionalidade. O Território Acaraí está traduzido por um conjunto de grupos que poderiam se auto identificar como pescadores artesanais, extrativistas, mulheres da samambaia, agricultores, quilombolas, do "Acaraí" . Qualquer definição dada no escopo dessa pesquisa seria arbitrariedade, tendo em vista que a pesquisa não objetivou desenhar os passos da autodeterminação junto aos sujeitos. Mas cada uma dessas categorias teria um potencial explícito, ou latente, de serem exploradas no sentido do autorreconhecimento, exigindo, contudo, outros passos a percorrer, não priorizados no recorte desta pesquisa (T18 p. 160).
\end{abstract}

Sendo assim, apesar de a importância da identificação própria, observamos que somente sete pesquisas (T13, T16, T18, T23, T24, T25, T29) fazem referência à "autoidentificação" das comunidades com uma ou outra categoria, e podemos ver que é uma preocupação recente pelas datas das pesquisas, sendo a primeira de 2011 . De acordo com os excertos apresentados, isto nos leva a pensar que as classificações das pesquisas que não fazem referência a essa autoidentificação foram feitas pelas/os autoras/es com base em estudos (visto a grande quantidade de caracterizações referenciadas de outras/os autoras/os) e/ou em muito menor número, em observações e acompanhamento das comunidades.

Esta identificação feita por pessoas externas às comunidades, pode seguir a mesma lógica que Said (1990) denuncia quando afirma que o "orientalismo é uma construção do ocidente". Segundo o autor, essa designação foi aceita primeiramente nos meios acadêmicos; em segundo lugar por questões epistemológicas e ontológicas; e em terceiro, com o intuito de fazer declarações ao seu respeito, descrevê-lo, colonizá-lo e governá-lo (SAID, 1990). Para o autor os grupos sociais que recebem a designação acabam sendo representados como "passivos", ou "sem voz" enquanto que quem pesquisa é o sujeito ativo, que dá voz a esses outros grupos que precisam de alguém que fale por eles. Sendo assim, estas representações são comuns no contexto das Ciências Sociais herdeira do 
colonialismo ocidental que, para Said, deixa de reconhecer seu papel nos processos de dominação global.

Assim, identidades se criam a partir da ótica de quem não se considera como parte dessas populações, muitas vezes desde a ótica colonialista com interesses específicos, explícitos ou não. É o que vemos, como por exemplo, com o caso das "ex-vilas" de pescadores ou de "remanescentes" de Quilombo, que tendem a descaracterizar e reduzir as comunidades. Nesse sentido, Arruti (1997), ao se referir aos "remanescentes de Quilombo", afirma que:

[...] as unidades de descrição das populações submetidas respondem, ao custo de uma brutal redução de sua alteridade, às necessidades de produção de unidades genéricas de intervenção e controle social, sendo que tais unidades variam segundo aquelas necessidades de controle e domínio (p. 14).

Sendo assim, por interesses sociais e políticos, as legislações e instituições vão alimentando essa imagem de que as comunidades tradicionais são parte de um passado a ser superado em prol do progresso. Porém, sua realidade atual é de luta para sobreviver, visando um futuro que muitas vezes não se encaixa na proposta de sociedade defendida pelo neoliberalismo, que se reproduz governo após governo.

\section{Considerações finais}

A análise do corpus documental da pesquisa ora apresentada nos permite compreender que o esforço para reconhecer e respeitar a autoidentificação das comunidades é minoria nas pesquisas analisadas. Porém, antes de julgar as pesquisas e suas/seus autoras/es, devemos questionar se não são simplesmente herdeiras/os da Ciência Social hegemônica, que por sua vez, é herdeira do colonialismo ocidental, que tende a se posicionar como "sujeito universal", e que historicamente pode ter contribuído para a naturalização das violências sofridas por estas populações.

Desde essa perspectiva hegemônica, designar grupos sociais enfraquecidos por violências históricas pode carregar intencionalidades de apagamento dos mesmos, como no caso das "ex-vilas" ou "remanescentes de Quilombos", que acabam sendo reproduzidas e legitimadas pela legislação. 
No entanto, no contexto político atual, dada a ascensão de governos, via processo da democracia representativa, que desprezam tanto as comunidades quanto o meio ambiente, faz se urgente questionar os processos que nos levaram até este momento histórico. Presenciamos uma pandemia de dimensões nunca antes vistas por estas gerações, ao mesmo tempo em que vemos uma enorme destruição de áreas naturais sem precedentes. As dinâmicas sociais que neste momento podem parecer que chegaram ao extremo devido ao atual contexto sanitário da Covid-19, na verdade somente foram colocadas ainda mais em evidência, porém, a partir da nossa realidade urbana e privilegiada era mais distante de ser vista, no entanto, nas comunidades tradicionais, há várias décadas, essa situação já era de vida ou morte.

Diálogos horizontais precisam ser estabelecidos entre pesquisadoras/es e comunidades, buscando construir um conhecimento que ouça de fato estes grupos, denunciando as injustiças que sofrem e contribuindo para a justiça socioambiental e a diversidade cultural.

\section{Referências bibliográficas:}

ARRUTI, José Maurício Andion. A emergência dos" remanescentes": notas para o diálogo entre indígenas e quilombolas. Mana, 1997, v. 3, n. 2, p. 7-38.

BARDIN, Laurence. Análise de conteúdo. Lisboa: Edições 70, 2009.

CAMPOS, Silmara Elena Alves de. Ser caiçara em Ilhabela: as construções de identidade nas tensões entre o passado e o presente. Dissertação de mestrado. Universidade Federal de São Carlos, 2008.

CASTRO, Roberta Rowsy Amorim; OLIVEIRA, Myriam Cyntia Cesar. Os termos "populações" e "comunidades" tradicionais e a apropriação dos conceitos no contexto amazônico. Mundo Amazónico, v. 7, n. 1-2, p. 47-70, 2016.

CARVALHO, Luiz Marcelo. A temática ambiental e a escola de 10 grau. 1989. Tese (Doutorado em Educação) - Faculdade de Educação, Universidade de São Paulo, São Paulo, 1989.

COSTA PEREIRA, José Verissimo da. Caboclo Amazônico. In: Tipos e Aspectos do Brasil. Rio de Janeiro: IBGE, 1975.

CUNHA, Manuela Carneiro da. Três peças de circunstância sobre o direito dos índios. In 
Cultura com aspas: e outros ensaios. São Paulo: Cosac Naify, 2009, p. 245-58.

CUNHA, Manuela Carneiro; ALMEIDA, Mauro. Quem são as populações tradicionais. Unidades de Conservação no Brasil. 2010.

DIEGUES, Antonio Carlos Sant'Ana. Etnoconservação: novos rumos para a conservação da natureza. Hucitec, 2000.

GONZALEZ, Lélia. Racismo e sexismo na cultura brasileira. Revista Ciências Sociais Hoje, Anpocs, 1984.

LIMA, Débora Magalhães. A construção histórica do termo caboclo: Sobre estruturas e representações sociais no meio rural amazônico. Novos Cadernos NAEA, [S.I.], v. 2, n. 2, dez, 1999.

MBEMBE, Achille. A Crítica da razão negra. Portugal: Antígona, 2014.

MEGID NETO, Jorge. Educação Ambiental como campo de conhecimento: a contribuição das pesquisas acadêmicas para sua consolidação no Brasil. Pesquisa em Educação Ambiental, São Carlos, v. 4, n. 2, p. 95-110, 2009.

MEGID NETO, Jorge; CARVALHO, Luiz Marcelo. Pesquisas de Estado da Arte: fundamentos, características e percursos metodológicos. In: ESCHENHAGEN, Maria Luise; CUARTAS, Gabriel Vélez.; MALDONADO, Carlos. La Producción de Conocimiento en la Universidad: Metodologías y Políticas de Investigación. Medellin: Editora de la Universidad de Antioquia, 2018

PACE, Richard. Abuso científico do termo 'caboclo'? Dúvidas de representação e autoridade. Boletim do Museu Paraense Emílio Goeldi. Ciências Humanas, 2006, vol. 1, no 3, p. 79-92.

PACHECO, Tania; FAUSTINO, Cristiane. A iniludível e desumana prevalência do racismo ambiental nos conflitos do mapa. IN: Injustiça ambiental e saúde no Brasil: o mapa de conflitos. Rio de Janeiro: Editora Fiocruz, 2013.

RIBEIRO, Darcy. O Povo Brasileiro. Global Editora, 2014.

SAID, E. W. Orientalismo: o Oriente como invenção do Ocidente. [S.I]: Editora Companhia das Letras, 1990.

SAMPAIO, Teodoro. O tupi na geografia nacional. [S.I], Brasiliana, 1987.

Link do Banco de teses e dissertações do Earte Brasil: http://www.earte.net/teses/ 